\title{
Treatment of Selective Mutism: Focus on Selective Serotonin Reuptake Inhibitors
}

\begin{abstract}
Yaman Kaakeh, Pharm.D., and Janice L. Stumpf, Pharm.D.
Selective mutism is a pediatric psychiatric disorder that occurs when a child consistently fails to speak in specific situations in which speaking is expected, such as at school and social gatherings, but speaks appropriately in other settings. Selective mutism often is diagnosed when a child starts school and does not talk to teachers or peers, but talks to family members at home; the condition is frequently accompanied by anxiety and shyness. Although the underlying etiology of the condition remains unclear, psychotherapy is the preferred initial treatment, with the support of parents and teachers. If the child does not respond to psychotherapy, addition of pharmacologic treatment should be considered, depending on the severity of symptoms and presence of other illnesses. Although data are limited to case reports and trials with small patient populations and short follow-up periods, some patients with selective mutism respond to therapy with selective serotonin reuptake inhibitors (SSRIs). Fluoxetine is the most studied SSRI as treatment for the condition, although further investigation is required to determine the optimal dosage and duration of therapy.

Key Words: selective mutism, selective serotonin reuptake inhibitors, SSRIs, fluoxetine, anxiety.

(Pharmacotherapy 2008;28(2):214-224)
\end{abstract}

\section{OUTLINE}

Etiology and Predisposing Factors

Epidemiology

Clinical Presentation and Diagnosis

Treatment

Psychotherapy

Pharmacotherapy

Limitations

Recommendations for Optimizing Therapy

Conclusion

Selective mutism is a psychiatric disorder that occurs in children. The condition is characterized

From the Department of Pharmacy Practice, School of Pharmacy and Pharmaceutical Sciences, Purdue University, West Lafayette, Indiana (Dr. Kaakeh); and the Drug Information Service, Department of Pharmacy Services, University of Michigan Health System and the College of Pharmacy, Ann Arbor, Michigan (Dr. Stumpf).

Address reprint requests to Janice L. Stumpf, Pharm.D., Department of Pharmacy Services, UH B2D301 SPC 5008, University of Michigan Health System, 1500 East Medical Center Drive, Ann Arbor, MI 48109-5008; e-mail: jlstumpf@umich.edu. by consistent failure to speak in specific situations in which speaking is expected, such as at school and social gatherings, despite speaking in other settings. ${ }^{1}$ Children with selective mutism can speak and comprehend the spoken language, but they withhold speech under certain conditions. Although relatively uncommon and generally self-limited, selective mutism can affect a child's socialization and academic development. Therapy consists of psychotherapy with or without pharmacologic intervention.

The terminology used to describe selective mutism has changed over the years as understanding of the disorder has evolved. ${ }^{2-4}$ Initially observed in 1877 by Kaussmaul, the disorder was termed aphasia voluntaria, which emphasized that children were making a voluntary decision to withhold speech. Elective mutism was the term used until publication of the Diagnostic and Statistical Manual of Mental Disorders, Fourth Edition (DSM-IV) in 1994, at which time the current term, selective mutism, was adopted. ${ }^{5}$ 
This term implies a true inability to speak in select situations rather than an elective decision to withhold speech.

\section{Etiology and Predisposing Factors}

It is not known whether selective mutism stems from a social phobia, or another anxiety or psychiatric disorder, such as obsessive-compulsive disorder or development disorder/delay. ${ }^{2-4,6-9}$ The pathogenesis of the condition is likely multifactorial. Selective mutism was once thought to be due to physical or emotional trauma to the child, thus a psychodynamic approach to therapy was advocated. However, in one case series, trauma, loss of a significant person, or other personal or family crisis accounted for the onset of selective mutism in only one third of 100 children with the diagnosis. ${ }^{10}$

Selective mutism has been characterized as a motivational disorder in that some children withhold speech because of severe situational anxiety. ${ }^{6}$ Some researchers believe that mutism is a learned behavior reinforced by the child's environment, and that some children may withhold speech for manipulative purposes. ${ }^{11}$ Selective mutism has also been described as a manifestation of family dysfunction, with the child's silence the result of oppositional behavior. ${ }^{3,6}$

Instead, it appears that biologically mediated shy temperament and anxiety may be key components in the etiology of selective mutism for most affected children., 8, 10, 12 Frequently, an affected child has a family history of selective mutism, shyness, or anxiety disorder in a close relative-particularly a parent-indicating a potential genetic link. 3, 7, 13,14 In one report, taciturnity (being habitually reserved and noncommunicative) was 2.5 times more frequent in first- than in third-degree relatives of children with selective mutism. ${ }^{13}$ In another study, $70 \%$ and $37 \%$ of affected children had first-degree relatives with a history of selective mutism and either social phobia or avoidant disorder, respectively. ${ }^{\top}$ Specific chromosomal abnormalities, namely deletion of the short arm of chromosome 18 , have been documented in two patients with selective mutism accompanied by similar patterns of speech delay and facial dysmorphisms. ${ }^{15,16}$

In addition to family history, factors that may predispose children to the development of selective mutism include immigration, early developmental risk factors (e.g., complications during pregnancy and delivery, premorbid speech or language disorders), and behavioral abnor- malities. ${ }^{10}$ Selective mutism frequently overlaps with other social anxiety disorders, and most affected children meet the diagnostic criteria for social phobia or avoidant disorder. ${ }^{7,12,17}$ In one study, 38 of 100 children with selective mutism had a speech and language disorder, such as difficulty with articulation or expressive language, before developing selective mutism. ${ }^{10}$ Poor understanding and criticism of the affected child's speech, resulting in embarrassment and lowered self-esteem, may lead to withdrawal and the development of selective mutism. In addition, $72 \%$ of children with selective mutism had a history of behavioral abnormalities, such as relationship problems, separation anxiety, and eating or sleep disorders during infancy and preschool age. ${ }^{10}$

\section{Epidemiology}

Selective mutism is rare and accounts for less than $1 \%$ of all patients seen in mental health settings. ${ }^{1}$ The reported incidence of selective mutism ranges from $0.18-2.0 \%{ }^{18-20}$ Differences in diagnostic criteria probably influence this variability. Selective mutism is $1.5-2.5$ times more common in girls than boys. ${ }^{7,10,12-14,19}$ No racial predilection has been documented, and its occurrence does not seem to be affected by socioeconomic status, ${ }^{14}$ although some reports have documented a higher prevalence in middleclass children. ${ }^{9,13}$

\section{Clinical Presentation and Diagnosis}

According to the DSM-IV-TR (Text Revision), a diagnosis of selective mutism requires failure to speak in specific situations in which speaking is expected, despite speaking at other times. ${ }^{1}$ In addition, the lack of speaking must interfere with achievement in school or social communication, persist for at least 1 month, and not be associated with an underlying developmental or psychiatric disorder. Selective mutism must be differentiated from mutism with an organic cause. With organic mutism, inability to speak is associated with hearing loss; brain tumor; or damage to the frontal lobe, brain stem, thalamus, or cerebellum as a result of insults such as trauma, infection, or surgery. ${ }^{21}$

Psychiatric disorders, including pervasive developmental disorder, schizophrenia, and mental retardation, may also manifest with lack of speech. ${ }^{3}$ These disorders must be ruled out before selective mutism can be diagnosed. ${ }^{1,3,21}$ In addition, children whose primary language is 
not English, and whose failure to speak is due to lack of knowledge or comfort with spoken English, are not considered to have selective mutism.

The onset of selective mutism is often insidious, occurring in the preschool years in over $80 \%$ of patients. ${ }^{14}$ The condition is usually not diagnosed until the child has started school at age 5-6 years, although it can develop in older children as well. If the child speaks at home, the parents may not be aware of the disorder. In one analysis, shyness was documented in $85 \%$ of children with selective mutism. ${ }^{10}$ Whereas shy children eventually warm up to others and start communicating within the first month of school, those with selective mutism do not. Teachers often have the most accurate information about the child's symptoms since school is the most common site for the failure to speak.

The extent of inhibition due to selective mutism can vary; severity of the condition is proportional to the severity of the child's social anxiety. 3, 20, 22 Some children avoid eye contact and withdraw completely in a social situation; others continue to make facial expressions and communicate nonverbally. Gestures, nodding or shaking the head, or monosyllabic sounds may be used to communicate. ${ }^{1}$ Concomitant symptoms may include enuresis and encopresis (fecal soiling), obsessive-compulsive features, and sleeping and eating disorders. ${ }^{9}, 10,14$

Selective mutism is generally self-limiting and may resolve spontaneously within a few weeks or months. In some patients, however, selective mutism and its accompanying conditions may persist for 20-30 years. ${ }^{23}$ In a follow-up study of 45 patients with selective mutism, complete remission or remarkable improvement occurred in 28 (62\%) after $3-15$ years. ${ }^{23}$ Compared with controls, patients with a history of selective mutism were less independent, less motivated with respect to education, and less self-confident. Of 25 patients who could be interviewed, 22 (88\%) described their selective mutism as a serious problem associated with intense suffering.

In another study, after a mean follow-up of 13 years, the rate of total resolution or marked improvement in patients with selective mutism was $82 \% .{ }^{24}$ However, a higher frequency of psychiatric disorders-especially phobic disorder-was documented in 33 patients compared with an age- and sex-matched control group ( $\mathrm{p}<0.005)$.

A comprehensive evaluation, including the child's medical and developmental history, family history, and speech patterns, is essential to assess possible causes of the lack of speech and to identify comorbid conditions. ${ }^{2,3}$ Essentially, selective mutism is a disease of exclusion that is diagnosed after other causes of the lack of speech have been ruled out. Correct diagnosis is crucial because inappropriate treatment may worsen the condition by exacerbating anxiety. A physical examination, including a formal speech and language assessment, should be conducted to identify neurologic, psychiatric, audiologic, and speech disorders. Of note, although with selective mutism the speech disturbance is restricted to a specific social situation, this is not the case with phonologic (related to speech sound) or expressive language disorders.

Standardized psychologic testing may be needed to assess academic status and evaluate for learning disabilities. Testing should include components of receptive language, expressive language, and phonology. Social interactions may be assessed through play or art therapy or through interviews with the child's teacher. An observational interview can provide useful information regarding the child's temperament, quality of interaction, and ability to communicate verbally and nonverbally. In addition, a parental interview may yield information about the child's developmental history and about speech patterns both inside and outside the home.

\section{Treatment}

The clinical significance of selective mutism can be argued, since the condition is generally self-limiting, resolving after several months in many cases. Medical attention may not be sought. However, selective mutism may persist for years, interfering with educational achievement, self-esteem, and socialization, with potential long-term consequences. ${ }^{20,23,25}$ Practitioners should consider the context, severity, and duration of selective mutism when determining appropriate therapy. Several approaches have been used, including both psychotherapy and pharmacotherapy.

Participation of family members in designing and implementing the treatment plan is critical. Punishment or coercion to force speech should be avoided; instead, a supportive environment should be provided in which speech can develop gradually. A school-based, individualized treatment plan involving the parents, teacher, health care provider, and possibly a speech therapist may reduce the child's anxiety and encourage communication. ${ }^{3,8,26}$ Treatment 
should focus on improving basic communication skills, which will allow the child to participate more readily in settings where speech is expected and reduce potential long-term detrimental effects of selective mutism. ${ }^{21}$

\section{Psychotherapy}

At one time, psychodynamic therapy focusing on identification and resolution of underlying psychologic conflicts was the preferred treatment of selective mutism. 3, 8, 22, 27 Because the child might not speak during sessions, therapists can use special art or play techniques to initiate communication. However, psychodynamic therapy can be time consuming, requiring longterm weekly sessions.

Over the last 2 decades, behavioral interventions or a combination of cognitive and behavioral techniques have become more commonly used as initial treatment for young children with selective mutism. Behavioral therapy is directed at removing all reinforcement of the mutism by gradually exposing the child to social situations and providing opportunities to practice communication. Specific strategies include positive reinforcement of verbal and nonverbal behaviors (contingency management and shaping) in conjunction with stimulus-fading interventions. In the latter, rewards are given for gradual increases in the number of people spoken to or situations spoken in. Relaxation techniques are taught that enable the child to manage increasing levels of speech-related anxiety with exposure to new speaking situations (systemic desensitization).

With cognitive therapy, clinical psychologists and other health care professionals seek to increase self-confidence and decrease anxiety by modifying self-expectations in social interactions. The child is helped to identify and change thoughts that reinforce mutism. In addition, techniques are developed to help the child recognize and cope with physiologic and psychologic indicators of emotional stress.

Family therapy as a primary intervention for selective mutism has not been systematically studied, although this approach can be useful if family issues are identified that may affect the child's condition. ${ }^{3,8,27}$ Speech therapy may benefit children with fluency or articulation problems; however, this approach appears to be less effective than cognitive-behavioral therapy or pharmacotherapy alone or in combination. ${ }^{22,27}$
Pharmacotherapy

Although psychotherapy plays an important role in the initial treatment of selective mutism, some patients may not respond. Addition of pharmacotherapy should then be considered, particularly for children whose condition is chronic or severe. ${ }^{3,28}$ Currently, no drugs are approved by the United States Food and Drug Administration (FDA) for treatment of selective mutism. In addition, reflecting the low prevalence of the condition, the literature consists mainly of case reports and clinical trials with relatively small patient populations. Yet despite scant published data regarding pharmacologic management, 71 (36\%) of 199 child and adolescent psychiatrists responding to a survey have prescribed psychotropic agentsmost commonly antidepressants-for patients with selective mutism. ${ }^{29}$ Drugs prescribed include phenelzine $e^{30,31}$ and selective serotonin reuptake inhibitors (SSRIs). ${ }^{32-43}$

\section{Phenelzine}

Phenelzine, an irreversible, nonselective monoamine oxidase inhibitor, was effective in four children with selective mutism described in two reports. ${ }^{30,31}$ The children, aged 5-7 years, received phenelzine 30-60 $\mathrm{mg} /$ day. In the first report, phenelzine $7.5 \mathrm{mg} 3$ times/day (1 $\mathrm{mg} / \mathrm{kg} /$ day) was started in a 7-year-old girl with a 2 -year history of selective mutism and associated shyness. ${ }^{30}$ The dosage was titrated to 37.5 $\mathrm{mg} / \mathrm{day}$, and within 6 weeks, the child began to speak freely outside the home. Further improvement was noted as the dosage was increased to $60 \mathrm{mg} /$ day.

In the second report, three children demonstrated similar responses; one had previously received fluoxetine therapy without success. ${ }^{31}$ Phenelzine treatment, administered for 24-60 weeks, was not associated with recurrence of mutism; one patient was followed for 8 years after the drug was discontinued and experienced no recurrence. Phenelzine was generally well tolerated, although weight gain, mild constipation, insomnia, low blood pressure, and bladder retention were documented. The authors postulated that selective mutism, like social phobia, might respond to the serotonergic and dopaminergic actions of this agent.

Because of significant food and drug interactions and dietary restrictions with phenelzine, the drug is administered only as a second-line 
agent for patients who fail treatment with an SSRI. However, phenelzine may be of particular benefit for a child with concomitant conditions such as enuresis, obsessive-compulsive symptoms, anxiety, or irritability.

\section{Selective Serotonin Reuptake Inhibitors}

No published trials were located comparing the SSRIs with other treatments for management of selective mutism. However, SSRIs may be considered first-line pharmacologic treatment for selective mutism because of the predominance of reports in the literature and due to the relative safety and established efficacy of these agents in other childhood psychiatric disorders. ${ }^{8,44}$ In one report, SSRIs were effective in 11 (65\%) of 17 children with selective mutism according to parent assessment. ${ }^{45}$

Although the specific mechanism by which SSRIs may improve selective mutism is unknown, there may be an underlying imbalance in central nervous system serotonin that is corrected by SSRI therapy. The SSRIs further serotonergic activity by reducing presynaptic serotonin reuptake, with only weak effects on other neurotransmitters. Some authors have suggested that disinhibition, a dopaminergic effect, may account for the rapid response (within $1 \mathrm{wk}$ ) noted in some patients with selective mutism who received SSRI therapy. ${ }^{35,41}$ In contrast, others reported efficacy only after 7-12 weeks of therapy, perhaps due to serotonin-mediated reductions in anxiety. $33,34,37,38$ Of the commercially available SSRIs, fluoxetine, fluvoxamine, sertraline, and paroxetine have been used as treatment for children with selective mutism (Table 1). ${ }^{32-43}$

Fluoxetine. Fluoxetine is the most studied SSRI administered in children with selective mutism; several clinical studies and case reports are cited in the literature. ${ }^{32-39,43}$ Interest in fluoxetine for selective mutism probably developed from its efficacy in treating social phobia in 10 (71\%) of 14 adults, as reported in $1992 .{ }^{46}$

In another 1992 report, a 12-year-old girl with a several-year history of social phobia and selective mutism was described. ${ }^{32}$ Her condition did not respond to two outpatient psychotherapy programs. After only slight improvement with desipramine, her treatment was changed to fluoxetine $20 \mathrm{mg}$ every other day for 7 days and then $20 \mathrm{mg} /$ day. Within 4 weeks, dramatic improvement was noted in her verbal communication with both peers and adults, and her social avoidance essentially resolved. This positive response was maintained at 7 months of continued fluoxetine therapy.

These findings led the same authors to conduct a randomized, double-blind, placebo-controlled evaluation of the efficacy of fluoxetine in children with selective mutism. ${ }^{33}$ The study was conducted in two phases and initially included 16 pediatric patients with selective mutism for a mean \pm SD of $5.8 \pm 2.7$ years. All 16 had social phobia or avoidant disorder of childhood; six also had other psychiatric disorders. The total number of psychiatric diagnoses was evenly distributed between treatment groups.

The first single-blind phase, in which all patients received placebo, lasted 2 weeks and was designed to eliminate placebo-responders. One child was subsequently excluded, and the rest were randomized to receive fluoxetine (six patients) or placebo (nine) in the second, 12week, double-blind phase. The investigators followed a dosage titration scale for the children receiving fluoxetine, starting with $0.2 \mathrm{mg} / \mathrm{kg}$ once/day for the first week, increasing to 0.4 $\mathrm{mg} / \mathrm{kg} /$ day for week 2 and to $0.6 \mathrm{mg} / \mathrm{kg} /$ day for the remaining 10 weeks.

The patient, psychiatrist, parents, and teachers assessed the changes in mutism, anxiety, shyness, and global clinical impression ratings and completed several assessment scales before the single-blind phase, at baseline just before the double-blind treatment phase, and every 2 weeks or 4 weeks (teachers) for 12 weeks. A mean mutism severity score was also calculated, based on the evaluation of speaking in common social situations.

Mean maximum fluoxetine dose was 21.4 $\mathrm{mg} /$ day (range 0.60-0.62 mg/kg/day). Overall, the fluoxetine-treated patients demonstrated improved group means in 28 of 29 rating scales, yet few changes were statistically significant. Effects were most apparent during weeks 8-12 of fluoxetine therapy. The parents documented significant improvements from baseline in eight of nine ratings over time. The differences between fluoxetine and placebo in mutism and global change scores were statistically significant and favored fluoxetine $(\mathrm{p}<0.0003$ and $\mathrm{p}<0.04$, respectively).

Although improvements from baseline were noted in six of nine clinician assessment tools, no statistically significant differences were noted between treatment groups. Significant improvements over time in all 10 ratings were reported by teachers for both treatment groups. Only the 
Table 1. Summary of Studies of Selective Serotonin Reuptake Inhibitors for Treatment of Selective Mutism

\begin{tabular}{|c|c|c|c|c|}
\hline $\begin{array}{l}\text { Drug, } \\
\text { Study Design }\end{array}$ & $\begin{array}{c}\text { Sex } \\
\text { Age (yrs) }\end{array}$ & Treatment & $\begin{array}{l}\text { Treatment } \\
\text { Duration }\end{array}$ & Outcome \\
\hline \multicolumn{5}{|l|}{ Fluoxetine } \\
\hline $\begin{array}{l}\text { Case report } \\
(\mathrm{n}=1)^{32}\end{array}$ & F, 12 & $\begin{array}{l}\text { Fluoxetine } 20 \text { mg q.o.d. x } 7 \text { days, } \\
\text { then } 20 \text { mg q.d. }\end{array}$ & $7 \mathrm{mo}$ & Improved within 4 wks \\
\hline $\begin{array}{l}\text { Case report } \\
(\mathrm{n}=1)^{39}\end{array}$ & F, 6 & Dosage not specified & NR & Improved \\
\hline $\begin{array}{l}\text { R, DB, PC; } \\
\text { fluoxetine } \\
\text { group }(n=6) \text {, } \\
\text { placebo } \\
\text { group }(n=9)^{33}\end{array}$ & $\begin{array}{l}6 \mathrm{M}, 9 \mathrm{~F} ; \\
\text { fluoxetine } \\
\text { group: } \\
9.1 \pm 2.3 \\
\text { (mean } \pm \mathrm{SD} \text { ); } \\
\text { placebo } \\
\text { group: } \\
8.1 \pm 2.7 \\
\text { (mean } \pm \mathrm{SD} \text { ) }\end{array}$ & $\begin{array}{l}\text { Placebo x } 2 \text { wks, then fluoxetine } \\
\text { titrated to } 0.6 \mathrm{mg} / \mathrm{kg} \text { q.d. or } \\
\text { placebo }\end{array}$ & $12 \mathrm{wks}$ & $\begin{array}{l}\text { Fluoxetine-treated patients improved } \\
\text { according to parent ratings, but not } \\
\text { according to most clinician and } \\
\text { teacher ratings }\end{array}$ \\
\hline $\begin{array}{l}\text { Case report } \\
(\mathrm{n}=1)^{35}\end{array}$ & $\mathrm{~F}, 4$ & $\begin{array}{l}\text { Fluoxetine } 4 \mathrm{mg} \text { q.d. initially, } \\
\text { then increased to } 8 \mathrm{mg} \text { q.d. }\end{array}$ & $1 \mathrm{yr}$ & $\begin{array}{l}\text { Improved in } 5 \text { days; positive response } \\
\text { maintained at } 1 \mathrm{yr}\end{array}$ \\
\hline $\begin{array}{l}\text { Case report } \\
(\mathrm{n}=1)^{36}\end{array}$ & F, 12 & $\begin{array}{l}\text { Placebo x } 13 \text { days, then } \\
\text { fluoxetine } 20 \text { mg q.d. }\end{array}$ & $6 \mathrm{wks}$ & $\begin{array}{l}\text { Improved within } 2 \text { wks; positive } \\
\text { response maintained } 1 \text { yr after drug } \\
\text { discontinuation }\end{array}$ \\
\hline $\begin{array}{l}\text { Open-label } \\
(n=21)^{34}\end{array}$ & $\begin{array}{l}5 \mathrm{M}, 16 \mathrm{~F} \\
5-14\end{array}$ & $\begin{array}{l}\text { Fluoxetine titrated to } 60 \mathrm{mg} \text { q.d. } \\
\text { (maximum); mean final daily } \\
\text { dose } 1.1 \mathrm{mg} / \mathrm{kg}\end{array}$ & 9 wks & $\begin{array}{l}\text { Improvement seen on all assessment } \\
\text { scales }\end{array}$ \\
\hline $\begin{array}{l}\text { Case report } \\
(\mathrm{n}=1)^{37}\end{array}$ & M, 8 & $\begin{array}{l}\text { Fluoxetine } 20 \text { mg q.d. x } 1 \text { mo, } \\
\text { then } 30 \mathrm{mg} \text { q.d. x } 3 \text { wks }\end{array}$ & 7 wks & Improved at $7 \mathrm{wks}$ \\
\hline $\begin{array}{l}\text { Case report } \\
(\mathrm{n}=1)^{43}\end{array}$ & F, 5 & $\begin{array}{l}\text { Fluoxetine } 20 \text { mg q.d., then } \\
30 \mathrm{mg} \text { q.d. + haloperidol } \\
0.5 \mathrm{mg} \text { b.i.d. }\end{array}$ & $9 \mathrm{mo}$ & $\begin{array}{l}\text { Improved within } 3 \mathrm{mo} \text {; improved } \\
\text { response after } 1 \text { mo of combination } \\
\text { therapy }\end{array}$ \\
\hline $\begin{array}{l}\text { Case report } \\
(n=4)^{38}\end{array}$ & $\mathrm{~F}, 5-17$ & $\begin{array}{l}\text { Fluoxetine } 0.3 \mathrm{mg} / \mathrm{kg} \text { q.d., } \\
\text { increased to } 0.6 \mathrm{mg} / \mathrm{kg} \text { q.d. } \\
(\mathrm{n}=1) ; \text { dosage } \mathrm{NR}(\mathrm{n}=3)\end{array}$ & $\begin{array}{l}18 \mathrm{mo} \\
(\mathrm{n}=1)\end{array}$ & All patients improved within $8-10$ wks \\
\hline \multicolumn{5}{|l|}{ Fluvoxamine } \\
\hline $\begin{array}{l}\text { Case report } \\
(\mathrm{n}=1)^{40}\end{array}$ & $F, 6.5$ & $\begin{array}{l}\text { Fluvoxamine } 50 \text { mg q.d. x } 2 \text { wks, } \\
\text { then } 100 \text { mg q.d. }\end{array}$ & $6 \mathrm{mo}$ & Improved after 2 wks 2 days \\
\hline \multicolumn{5}{|l|}{ Sertraline } \\
\hline $\begin{array}{l}\text { 3-phase, DB, } \\
\text { single-case } \\
\text { design } \\
(\mathrm{n}=5)^{41}\end{array}$ & $\begin{array}{l}1 \mathrm{M}, 4 \mathrm{~F} \\
5-11\end{array}$ & $\begin{array}{l}\text { Placebo x } 2-6 \text { wks, then } \\
\text { sertraline } 50 \text { mg q.d. x } 2 \text { wks, } \\
\text { then } 100 \text { mg q.d. x } 6-10 \text { wks }\end{array}$ & $8-12$ wks & $\begin{array}{l}\text { All patients improved by week } 16 \\
\text { according to parent ratings }\end{array}$ \\
\hline \multicolumn{5}{|l|}{ Paroxetine } \\
\hline $\begin{array}{l}\text { Case report } \\
(\mathrm{n}=1)^{42}\end{array}$ & F, 8 & Paroxetine 5 mg q.d. & 3 yrs & Improved within 2-3 wks \\
\hline
\end{tabular}

change in rating for anxiety was significantly more improved with fluoxetine than placebo; however, fluoxetine recipients had higher scores throughout the study, from baseline to the end of treatment.

No significant improvements were noted in the few patient self-ratings collected. The proportion of patients deemed responders was higher in the fluoxetine group according to evaluations conducted by parents, but not by clinicians or teachers. Of note, patient and teacher assessment of improvements in individual patients were correlated $(\mathrm{p} \leq 0.03)$. Most patients remained symptomatic at the end of the study; the number of patients whose selective mutism resolved was not provided. Adverse effects with fluoxetine were minimal and did not differ significantly from those with placebo.

Although this study provided important information regarding the potential efficacy of fluoxetine therapy in children with selective mutism, interpretation of the results is limited by 
the small sample size and more severe symptoms in the fluoxetine group at baseline. Because much of the fluoxetine benefit was noted after 8 weeks, a longer treatment duration at the higher doses might affect outcomes. Continued mutism with the treating clinician while the child's symptoms are improving at home or in school is consistent with previous reports. However, the authors surmised that early treatment effects noted in the home and neighborhood by parents might be extended to improvements in school with a longer treatment duration.

The time of treatment in relation to the school year might also have influenced the results. This study was conducted in the second half of the school year. Starting therapy in the summer months might improve the chances of a positive outcome. At the beginning of the school year, peers and teachers would have fewer preconceived notions regarding lack of speaking to overcome.

Another group of authors evaluated the efficacy of fluoxetine for treatment of selective mutism in 21 children (aged 5-14 yrs) with concurrent anxiety disorders in a 9-week openlabel trial. ${ }^{34}$ Weekly supportive psychotherapy was provided to all patients during the study. In an attempt to decrease adverse effects, fluoxetine was slowly titrated from $1.25 \mathrm{mg}$ /day the first week to $20 \mathrm{mg} /$ day after approximately 4 weeks in the first 10 children enrolled. If no clinical improvement occurred by week 7 , the fluoxetine dosage was increased to $40 \mathrm{mg}$ /day and again to $60 \mathrm{mg}$ /day after 2 weeks if needed. The protocol was revised for faster fluoxetine titration in the next 11 patients. Assessments were conducted by a psychiatrist and included patients' selfratings and parents' evaluation of symptoms and behavior.

Mean fluoxetine dose at the end of the trial was $28.1 \mathrm{mg} / \mathrm{day}(1.1 \mathrm{mg} / \mathrm{kg} / \mathrm{day}$, range $10-60$ $\mathrm{mg} /$ day); optimal response was noted with 20 $\mathrm{mg} /$ day. At the end of 9 weeks, 16 (76\%) of 21 children showed improvement on the Clinical Global Improvement Scale. The response rate was similar for boys and girls and was inversely correlated with age.

Statistically significant improvements in scores were seen with all clinical outcome instruments at week 9. On the Children's Global Assessment Scale, with scores of 0-100 indicating lowest to highest function, the patients improved from a mean \pm SD score of $47.1 \pm 9.0$ at baseline to 67.5 $\pm 13.0(p<0.001)$. Similarly, on the Liebowitz Social Anxiety Scale and the Social Avoidance
Scale scores, both ranging from 0-72, with lower scores predicting better function, improved from $48.2 \pm 13.7$ to $27.5 \pm 18.9(\mathrm{p}<0.001)$ and from $45.4 \pm 13.1$ to $27.5 \pm 22.1 \quad(\mathrm{p}<0.001)$, respectively. Treatment benefits as assessed by patients $(p<0.001)$ and parents $(p<0.005)$ were also documented on the Social Behavior Scales.

Nine (43\%) of the 21 patients had adverse effects, including excitement or disinhibition (four patients), insomnia (two), jitteriness (two), and headache (two). These were generally shortlived, lasting less than 1 week. However, therapy was discontinued in two of the children with behavioral disinhibition. No changes were observed in heart rate, blood pressure, or weight.

The authors concluded that fluoxetine is safe and effective for treatment of selective mutism in conjunction with psychotherapy in children aged 5 years or older. However, the lack of a placebo group and the small study population may limit interpretation of results. Fluoxetine was gradually titrated to avoid potential dose-related adverse effects, such as behavioral disinhibition. However, the slow initial titration (4-9 wks), muddled by the titration protocol change, may have affected outcomes. Complete remission of selective mutism may require a longer treatment duration at the minimal effective dose than was provided by the 9-week study duration.

Success with fluoxetine therapy has also been documented in case reports involving patients with selective mutism. ${ }^{35-39}$ One group described fluoxetine administration in a 4-year-old girl with a 15-month history of selective mutism. ${ }^{35}$ After presenting with a 9-month history of the disorder, the child benefited somewhat from a 12-week outpatient preschool diagnostic and intervention day program. However, she still was not speaking at the end of the program or after another 3 months of weekly behavioral treatment. Fluoxetine $4 \mathrm{mg} /$ day was then started, and within 5 days, the girl began to speak in familiar settings. The dose was increased to 8 $\mathrm{mg}$ /day by day 12 , and she was talking comfortably in all settings by day 20 .

After 18 months, the patient's scores for internalizing symptoms, withdrawal and somatic complaints, and difficulties with mood and adaptability decreased from clinically significant to having borderline significance. In contrast, scores indicating social problems, hyperactivity, and distractibility worsened as the child responded to fluoxetine therapy. No adverse effects were noted. Fluoxetine and monthly family therapy were still effective after 1 year. 
The treatment duration required to maintain response for selective mutism remains unclear. One author described a 12-year-old Turkish girl with an 8-year history of selective mutism who had a sustained response after 6 weeks of SSRI therapy. ${ }^{36}$ The patient would speak only to her mother and a few siblings and friends; she used gestures and writing to communicate with others. Her communication levels did not change after a 13-day placebo trial. Fluoxetine $20 \mathrm{mg} /$ day was then begun. Within 2 weeks, the patient was less withdrawn, and started talking to her father and brothers as well as her physician. Fluoxetine therapy was continued for 4 more weeks with no adverse effects. Treatment was then stopped, and the patient continued speaking during the next 12 months.

In another report, an 8-year-old boy was hospitalized after 4 years of selective mutism accompanied by 1 year of aggressive behavior. ${ }^{37}$ Two weeks after admission, fluoxetine $20 \mathrm{mg} /$ day was started. After 1 month, the dose was increased to $30 \mathrm{mg} / \mathrm{day}$ ( $1 \mathrm{mg} / \mathrm{kg} / \mathrm{day}$ ), and behavioral interventions were begun. After 3 weeks, the patient started speaking.

The benefits of fluoxetine were also demonstrated in four girls aged 5-17 years who had not responded to $1-2$ years of psychotherapy. ${ }^{38}$ One girl showed marked improvement within 6 weeks of the start of fluoxetine therapy; full effects were noted within 3 months. In another case report, a 6-year-old girl with a 2-year history of selective mutism after poor response to psychotherapy improved with fluoxetine therapy. ${ }^{39}$ However, dosage and time to effect were not provided.

Clinical trials of drug combinations in patients with selective mutism have not been conducted. However, addition of haloperidol to fluoxetine therapy benefited one patient with Tourette's syndrome and selective mutism. ${ }^{43}$ This child, who developed selective mutism at 5 years of age, initially responded to treatment with fluoxetine $20 \mathrm{mg} /$ day and behavioral therapy, and was speaking to family members after 3 months. After a trial with clonidine for increasingly aggressive behavior, haloperidol $0.5 \mathrm{mg}$ at bedtime was added to the patient's regimen of fluoxetine $30 \mathrm{mg} /$ day. Haloperidol was increased to twice/day without notable adverse effects. Within 1 month of this combination therapy, the child was communicating in various settings with diminished vocal and motor tics.

Fluvoxamine. Unlike fluoxetine, no clinical studies have formally evaluated fluvoxamine therapy for selective mutism. However, this SSRI has been effective in the management of a variety of pediatric anxiety disorders. ${ }^{47}$ In one case report, fluvoxamine was administered to a 6.5year-old girl with selective mutism and obsessivecompulsive traits. ${ }^{40}$ The child's social withdrawal tendency began when she was 4 years old; she was diagnosed with selective mutism the next year at school entry. Several months of psychotherapy were ineffective. Fluvoxamine 50 $\mathrm{mg} /$ day $(1.8 \mathrm{mg} / \mathrm{kg} /$ day $)$ was started and was increased to $100 \mathrm{mg} /$ day when no response was noted after 2 weeks. Within 2 days, the patient's verbal communication improved dramatically and her obsessive symptoms completely resolved.

Within 4 weeks, however, the child began to experience a hypomanic syndrome characterized by hyperactivity, decreased sleep, distractibility, and self-endangering behavior (e.g., jumping from furniture). These symptoms improved with reduction of the fluvoxamine dosage to an alternating schedule of $50 \mathrm{mg} / \mathrm{day}$ and 100 $\mathrm{mg} /$ day, and resolved after the start of lithium carbonate therapy. Six months later, the selective mutism remained in relative remission, but manic symptoms were noted and fluvoxamine was discontinued. Nine months after the SSRI was discontinued, the patient was still speaking, although oppositional behaviors remained problematic, and some obsessive symptoms recurred.

Sertraline. In 1999, a group of authors reported the efficacy of sertraline as treatment for selective mutism. ${ }^{41}$ Five children, aged 5-11 years, were included in this three-phase, 16-week, doubleblind study. The first phase consisted of 2 weeks with no drug treatment. The second phase involved administration of placebo for 2-6 weeks. In the third phase, each child was given sertraline $50 \mathrm{mg} /$ day for 2 weeks followed by 100 $\mathrm{mg} /$ day for $6-10$ weeks, depending on the length of the placebo phase. No group changes in mutism, anxiousness, and shyness were measured. Weekly parent Goal Attainment Scale ratings showed improvements in four of the five patients within 1 week of the start of sertraline therapy; response was noted in the remaining patient in week 5 of active treatment.

At week 16, parent ratings on the Goal Attainment Scale indicated improved levels of speech in all five patients. Similarly, parents observed some improvement in spontaneous speaking during sertraline therapy in four children. Teachers, however, observed speaking 
in only two of these four at school. All five patients continued receiving sertraline 100 $\mathrm{mg} /$ day and maintained improvements in mutism, anxiety, and shyness ratings 4 weeks after study end. By 20 weeks after study end, three patients no longer met the diagnostic criteria for selective mutism: two who were receiving sertraline $50 \mathrm{mg} /$ day and one whose drug therapy was discontinued. The remaining two patients continued receiving sertraline 100 $\mathrm{mg} /$ day. Their mutism improved in some settings, although they still did not speak in the classroom.

Acceptability of sertraline treatment and overall patient compliance were high. Few adverse effects occurred, although insomnia was reported by one patient 2 weeks after the dose increase in phase 3.

In addition to its small sample size and lack of standardized scales to assess selective mutism, this study is limited by its nonconcurrent multiple baseline design and, subsequently, the inability to apply statistical methods to the data. Although each patient improved relative to baseline, the onset of increased speech did not correspond to the start of sertraline therapy. Therefore, the internal validity of the multiple baseline design was not established.

Paroxetine. The efficacy of paroxetine was reported in an 8-year-old girl with significant social anxiety disorder and selective mutism that was diagnosed when she was 5 years old. ${ }^{42}$ The child refused to speak to anyone except her parents and siblings, and only at home. Paroxetine $5 \mathrm{mg}$ at bedtime was started without concomitant psychotherapy. Within 2-3 weeks, her family and teachers noted a dramatic response in both selective mutism and anxiety; the patient was communicating verbally at school and in other social settings. She received paroxetine for 3 years without relapse of selective mutism.

\section{Limitations}

The few clinical studies and case reports available regarding SSRI administration to treat selective mutism have several notable limitations. Most trials had small sample sizes and included children from a referred sample. These patients might have more severe symptoms than a general patient population with selective mutism. Fluoxetine was the SSRI administered in most reports; doses of other SSRIs were relatively low, making assessment of comparative efficacy difficult. In addition, because only a few doubleblind studies exist, a placebo effect cannot be fully excluded. Further, the positive outcomes noted in case reports may be misleading, since reports of similar patients in whom treatment was unsuccessful are less likely to be published.

The trials were short, consisting of only 6-10 weeks of SSRI therapy. ${ }^{33,34,41}$ Follow-up was reported in only one study. ${ }^{41}$ No validated assessment tools have been established for evaluating treatment outcomes in children with selective mutism. Instead, assessments of efficacy vary; for example, modified scales for social anxiety, behavior, and depression have been used. ${ }^{41}$

The setting of observations may also affect results, since children may remain mute at the clinic while improving at home and at school. In addition, variable timing of SSRI therapy may affect response rates; efficacy might be enhanced if SSRIs were started before or early in the school year. $^{33}$

\section{Recommendations for Optimizing Therapy}

The long-term consequences of selective mutism are unclear, but the condition may be associated with impaired school achievement, self-esteem, and socialization. ${ }^{23}$ Some authors have argued that early diagnosis and intervention result in a better prognosis, ${ }^{35}$ but this is largely unproven. Because of the inherent risks and sparse data regarding the long-term benefits of drug therapy, management of selective mutism should begin with psychotherapy. ${ }^{3,}$ 8, 27 Behavioral interventions or cognitive-behavioral therapy alone or in conjunction with family and speech therapies may be indicated, depending on the individual patient. Treatment should focus on encouraging the child to interact and communicate by reducing symptoms of anxiety and avoiding reinforcement of the mutism. ${ }^{2,3}$

If the child does not respond to psychotherapy, the decision to add drug therapy depends on factors such as the severity of selective mutism symptoms, history of previous treatment attempts, and identification of comorbid illnesses that might benefit from therapy (e.g., anxiety, obsessive-compulsive disorder). The support by parents and teachers of a multimodal approach incorporating both psychotherapy and pharmacologic management is needed to increase the likelihood of positive outcomes.

The SSRIs are well tolerated; the frequency of 
cardiac events and anticholinergic adverse effects is lower than that with tricyclic antidepressants. Adverse effects noted with SSRIs in clinical trials and case reports of children with selective mutism were generally described as mild and transient. These effects included gastrointestinal and sleep disturbances, jitteriness, drowsiness, headache, and decreased appetite. However, increases in oppositional and disinhibitory behavior and hypomania also were reported. ${ }^{34,40}$ The patient's family should also be made aware of the risk of serotonin syndrome and withdrawal reactions.

In 2004, the FDA required that SSRI manufacturers add to package labeling a black-box warning of the potential for suicidal ideation and behaviors after administration of these agents to pediatric patients. ${ }^{48}$ More recently, a metaanalysis did not document a statistically significant increased risk of suicidality with obsessive-compulsive disorder or other anxiety disorders. ${ }^{49}$ However, close monitoring of patients is recommended, especially during the first few months of SSRI therapy.

Randomized, placebo-controlled trials involving larger numbers of patients followed for longer durations are required to delineate the optimal course of SSRI therapy for selective mutism. Since most experience with SSRI treatment in these patients to date involves fluoxetine, this agent is preferred. One study reported optimal efficacy with a dosage of $20 \mathrm{mg} /$ day. $^{34}$ Response has occurred as early as within 1 week of the start of SSRI treatment but may not be apparent until up to 12 weeks. Thus, it seems prudent to administer adequate SSRI doses for at least 3 months before deeming therapy a failure. The optimal treatment duration after resolution of selective mutism also remains unclear. In one case report, therapy was continued for 3 years. ${ }^{42}$ In contrast, sustained remissions of up to 1 year have been documented after discontinuation of SSRI therapy. ${ }^{36,40,41}$

\section{Conclusion}

Selective mutism is a rare psychiatric disorder in which a child consistently fails to speak in specific situations in which speaking is expected, but speaks appropriately in other settings. Although children with the condition are often treated with psychotropic agents, only limited literature describes the efficacy of drug therapy for selective mutism. After the failure of psychotherapy alone, a trial with fluoxetine may be suggested, with close monitoring for serious adverse effects associated with SSRI administration in children and adolescents. Much remains to be learned about the course of selective mutism, including the choice and required duration of therapy.

\section{References}

1. American Psychiatric Association. Diagnostic and statistical manual of mental disorders, fourth edition, text revision (DSMIV-TR). Washington, DC: American Psychiatric Association, 2000.

2. Krysanski VL. A brief review of selective mutism literature. J Psychol 2003;137:29-40.

3. Dow SP, Sonies BC, Scheib D, Moss SE, Leonard HL. Practical guidelines for the assessment and treatment of selective mutism. J Am Acad Child Adolesc Psychiatry 1995;34:836-46.

4. Sharp WG, Sherman C, Gross AM. Selective mutism and anxiety: a review of the current conceptualization of the disorder. J Anx Dis 2007;21:568-79.

5. American Psychiatric Association. Diagnostic and statistical manual of mental disorders, fourth edition (DSM-IV). Washington, DC: American Psychiatric Association, 1994.

6. Cohan SL, Price JM, Stein MB. Suffering in silence: why a developmental psychopathology perspective on selective mutism is needed. J Dev Behav Pediatr 2006;27:341-55.

7. Black B, Uhde TW. Psychiatric characteristics of children with selective mutism: a pilot study. J Am Acad Child Adolesc Psychiatry 1995;34:847-56.

8. Kumpulainen K. Phenomenology and treatment of selective mutism. CNS Drugs 2002;16:175-80.

9. Kristensen H. Selective mutism and comorbidity with developmental disorder/delay, anxiety disorder, and elimination disorder. J Am Acad Child Adolesc Psychiatry 2000;39:249-56.

10. Steinhausen HC, Juzi C. Elective mutism: an analysis of 100 cases. J Am Acad Child Adolesc Psychiatry 1996;35:606-14.

11. Krohn DD, Weckstein SM, Wright HL. A study of the effectiveness of a specific treatment for elective mutism. J Am Acad Child Adolesc Psychiatry 1992;31:711-18.

12. Dummit ES, Klein RG, Tancer NK, Asche B, Martin J, Fairbanks JA. Systematic assessment of 50 children with selective mutism. J Am Acad Child Adolesc Psychiatry 1997;36:653-60.

13. Steinhausen HC, Adamek R. The family history of children with elective mutism: a research report. Eur Child Adolesc Psychiatry 1997;6:107-11.

14. Kolvin I, Fundudis T. Elective mute children: psychological development and background factors. J Child Psychol Psychiatry 1981;22:219-32.

15. Simons D, Goode S, Fombonne E. Elective mutism and chromosome 18 abnormality. Eur Child Adolesc Psychiatry 1997;6:112-14.

16. Grosso S, Cioni M, Pucci L, Morgese G, Balestri P. Selective mutism, speech delay, dysmorphisms, and deletion of the short arm of chromosome 18: a distinct entity [letter]? J Neurol Neurosurg Psychiatry 1999;67:830-1.

17. Yeganeh R, Beidel DC, Turner SM, Pina AA, Silverman WK. Clinical distinctions between selective mutism and social phobia: an investigation of childhood psychopathology. J Am Acad Child Adolesc Psychiatry 2003;42:1069-75.

18. Kopp S, Gillberg C. Selective mutism: a population-based study: a research note. J Child Psychol Psychiatry 1997;38:257-62

19. Kumpulainen K, Räsänen E, Raaska H, Somppi V. Selective mutism among second-graders in elementary school. Eur Child Adolesc Psychiatry 1998;7:24-9.

20. Bergman RL, Piacentini J, McCracken JT. Prevalence and description of selective mutism in a school-based sample. J Am Acad Child Adolesc Psychiatry 2002;41:938-46. 
21. Gordon N. Mutism: elective or selective, and acquired. Brain Dev 2001;23:83-7.

22. Schwartz RH, Shipon-Blum E. "Shy" child? Don't overlook selective mutism. Contemp Pediatr 2005;22(7):30-9.

23. Remschmidt H, Poller M, Herpertz-Dahlmann B, Hennighausen K, Gutenbrunner C. A follow-up study of 45 patients with elective mutism. Eur Arch Psychiatry Clin Neurosci 2001;251:284-96.

24. Steinhausen HC, Wachter M, Laimböck K, Metzke CW. A long-term outcome study of selective mutism in childhood. J Child Psychol Psychiatr 2006;47:751-6.

25. Kristensen $\mathbf{H}$. Multiple informants' report of emotional and behavioural problems in a nation-wide sample of selective mute children and controls. Eur Child Adolesc Psychiatry 2001;10:135-42.

26. Rye MS, Ullman D. The successful treatment of long-term selective mutism: a case study. J Behav Ther Exp Psychiatry 1999;30:313-23.

27. Cohan SL, Chavira DA, Stein MB. Practitioner review: psychosocial interventions for children with selective mutism: a critical evaluation of the literature from 1990-2005. J Child Psychol Psychiatr 2006;47:1085-97.

28. Stein MT, Rapin I, Yapko D. Selective mutism. J Dev Behav Pediatr 2001;22(2 suppl):S123-6.

29. Carlson JS, Kratochwill TR, Johnston H. Prevalence and treatment of selective mutism in clinical practice: a survey of child and adolescent psychiatrists. J Child Adolesc Psychopharmacol 1994:4:281-91.

30. Golwyn DH, Weinstock RC. Phenelzine treatment for elective mutism: a case report. J Clin Psychiatry 1990;51:384-5.

31. Golwyn DH, Sevlie CP. Phenelzine treatment of selective mutism in four prepubertal children. J Child Adolesc Psychopharmacol 1999;9:109-13.

32. Black B, Uhde TW. Elective mutism as a variant of social phobia. J Am Acad Child Adolesc Psychiatry 1992;31:1090-4.

33. Black B, Uhde TW. Treatment of elective mutism with fluoxetine: a double-blind, placebo-controlled study. J Am Acad Child Adolesc Psychiatry 1994:33:1000-6.

34. Dummit ES, Klein RG, Tancer NK, Asche B, Martin J. Fluoxetine treatment of children with selective mutism: an open trial. J Am Acad Child Adolesc Psychiatry 1996;35:615-21.

35. Wright HH, Cuccaro ML, Leonhardt TV, Kendall DF, Anderson JH. Case study: fluoxetine in the multimodal treatment of a preschool child with selective mutism. J Am
Acad Child Adolesc Psychiatry 1995;34:857-62.

36. Motavalli N. Fluoxetine for (s)elective mutism [letter]. J Am Acad Child Adolesc Psychiatry 1995;34:701-2.

37. Guna-Dumitrescu L, Pelletier G. Successful multimodal treatment of a child with selective mutism: a case report [letter]. Can J Psychiatry 1996;41:417.

38. Berger I, Jaworowski S, Gross-Tsur V. Selective mutism: a review of the concept and treatment. Isr Med Assoc J 2002;4(12):1135-7.

39. Boon F. The selective mutism controversy (continued) [letter] J Am Acad Child Adolesc Psychiatry 1994;33:283.

40. Lafferty JE, Constantino JN. Fluvoxamine in selective mutism. J Am Acad Child Adolesc Psychiatry 1998;37:12-13.

41. Carlson JS, Kratochwill TR, Johnston HF. Sertraline treatment of 5 children diagnosed with selective mutism: a single-case research trial. J Child Adolesc Psychopharmacol 1999;9: 293-306.

42. Lehman RB. Rapid resolution of social anxiety disorder, selective mutism, and separation anxiety with paroxetine in an 8-year-old girl [letter]. J Psychiatry Neurosci 2002;27:124-5

43. Rupp SN. Haloperidol for Tourette's disorder plus selective mutism [letter]. J Am Acad Child Adolesc Psychiatry 1999;38:7.

44. Murphy TK, Bengtson MA, Tan JY, Carbonell E, Levin GM. Selective serotonin reuptake inhibitors in the treatment of paediatric anxiety disorders: a review. Int Clin Psychopharmacol 2000;15(suppl 2):S47-63.

45. Schwartz RH, Freedy AS, Sheridan MJ. Selective mutism: are primary care physicians missing the silence? Clin Pediatr 2006;45:43-8.

46. Black B, Uhde TW, Tancer ME. Fluoxetine for the treatment of social phobia [letter]. J Clin Psychopharmacol 1992;12:293-5.

47. Research Unit on Pediatric Psychopharmacology Anxiety Study Group. Fluvoxamine for the treatment of anxiety disorders in children and adolescents. N Engl J Med 2001;344:1279-85.

48. U.S. Food and Drug Administration. Public health advisory suicidality in children and adolescents being treated with antidepressant medications, October 15, 2004. Available from http://www.fda.gov/cder/drug/antidepressants/SSRIPHA2004l.h tm. Accessed May 15, 2007.

49. Bridge JA, Iyengar S, Salary CB, et al. Clinical response and risk for reported suicidal ideation and suicide attempts in pediatric antidepressant treatment. JAMA 2007;297:1683-96. 